\title{
New Technologies for Repairing Aging Cables in Nuclear Power Plants
}

\author{
KL Simmons \\ LS Fifield \\ MP Westman
}

September 2013

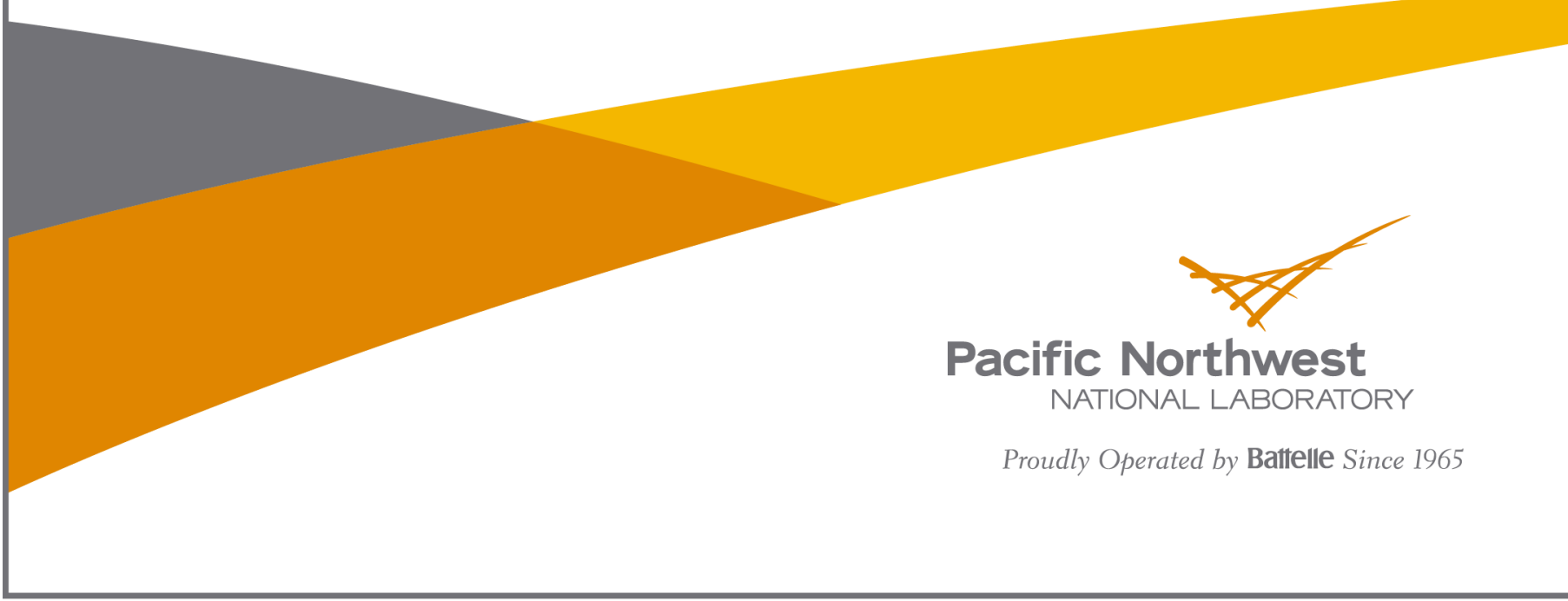




\title{
DISCLAIMER
}

This report was prepared as an account of work sponsored by an agency of the United States Government. Neither the United States Government nor any agency thereof, nor Battelle Memorial Institute, nor any of their employees, makes any warranty, express or implied, or assumes any legal liability or responsibility for the accuracy, completeness, or usefulness of any information, apparatus, product, or process disclosed, or represents that its use would not infringe privately owned rights. Reference herein to any specific commercial product, process, or service by trade name, trademark, manufacturer, or otherwise does not necessarily constitute or imply its endorsement, recommendation, or favoring by the United States Government or any agency thereof, or Battelle Memorial Institute. The views and opinions of authors expressed herein do not necessarily state or reflect those of the United States Government or any agency thereof.

\author{
PACIFIC NORTHWEST NATIONAL LABORATORY \\ operated by \\ BATTELLE \\ for the \\ UNITED STATES DEPARTMENT OF ENERGY \\ under Contract DE-AC05-76RL01830
}

Printed in the United States of America
Available to DOE and DOE contractors from the Office of Scientific and Technical Information,
P.O. Box 62, Oak Ridge, TN 37831-0062;
ph: (865) 576-8401
fax: (865) 576-5728
email: reports@adonis.osti.gov

\author{
Available to the public from the National Technical Information Service, \\ U.S. Department of Commerce, 5285 Port Royal Rd., Springfield, VA 22161 \\ ph: (800) 553-6847 \\ fax: (703) $605-6900$ \\ email: orders@ntis.fedworld.gov \\ online ordering: http://www.ntis.gov/ordering.htm
}

This document was printed on recycled paper.

(9/2003) 


\title{
New Technologies for Repairing Aging Cables in Nuclear Power Plants
}

\author{
KL Simmons \\ LS Fifield \\ MP Westman
}

September 2013

Prepared for

the U.S. Department of Energy

under Contract DE-AC05-76RL01830

Pacific Northwest National Laboratory

Richland, Washington 99354 



\section{Executive Summary}

The goal of this project is to demonstrate a proof-of-concept for a technique to repair aging cables that have been subjected to degradation associated with long-term thermal and radiation exposure in nuclear power plants. The physical degradation of the aging cables manifests itself primarily as cracking and increased brittleness of the polymeric electrical insulation. Therefore, the proposed cable-repair concept comprises development of techniques to impart a softening agent within the deteriorated polymer insulation jacket so as to regain the ability of the insulation to stretch without failing and possibly to heal existing cracks in the insulation.

Our approach is to use commercially available ethylene-propylene rubber (EPR) as the relevant test material, demonstrate the adsorption of chemical treatments in the EPR and quantify changes in resulting physical and mechanical properties. EPR cable samples have been thermally treated in air to produce specimens corresponding to the full range of cable age-performance points from new $(>350 \%$ elongation at break) to end-of-life ( $<50 \%$ elongation at break).

The current focus is on two chemical treatments selected as candidates for restoring age-related cable elasticity loss: a rubber plasticizer and a reactive silane molecule. EPR specimens of 200,150, 100, and $50 \%$ elongation at break have been soaked in the candidate chemical treatments and the kinetics of chemical uptake, measured by change in mass of the samples, has been determined. Mechanical properties as a function of aging and chemical treatment have been measured including ultimate tensile strength, tensile modulus at 50\% strain, elongation at break, and storage modulus. Dimensional changes with treatment and changes in glass transition temperature were also investigated. These ongoing experiments are expected to provide insight into the physical-chemical nature of the effect of thermal degradation on EPR rejuvenation limits and to advance novel methods for restoring the ability of degraded EPR to be compliant and resist fracture.

The results of this research reveal that absorption of chemical treatments can lower the glass transition temperature and modulus of EPR. Chemical treatments pursued thus far have proven ineffective at restoring EPR strength and elongation at break. Future work will combine the plasticizer modalities found to successfully increase the volume of the EPR, reduce EPR glass transition temperature and reduce EPR modulus with promising chemistries that will repair the damage of the polymer, potentially using the plasticizer as a host for the new chemistry. 



\section{Acronyms}

$\begin{array}{ll}\text { EAB } & \text { Elongation at break } \\ \text { EPR } & \text { Ethylene-propylene rubber } \\ \text { P-R } & \text { Plasticizer R } \\ \text { S-T } & \text { Silane T }\end{array}$





\section{Contents}

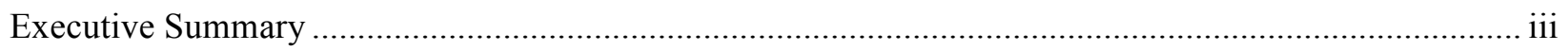

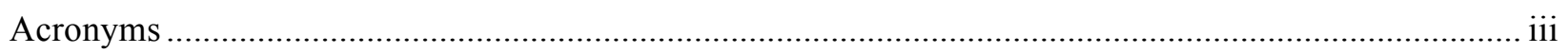

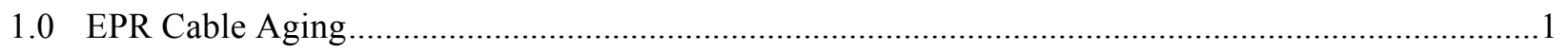

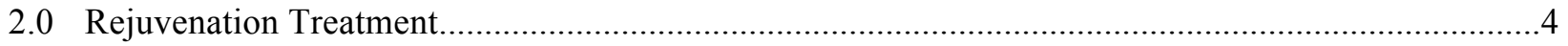

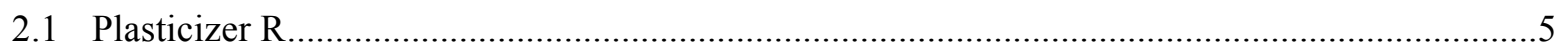

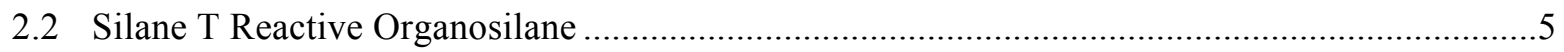

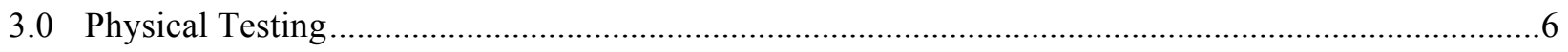

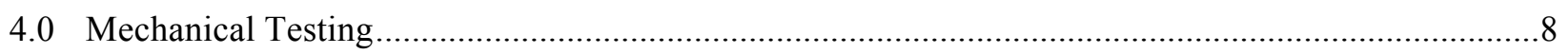

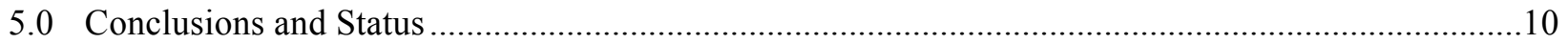




\section{Figures}

Figure 1.1. EPR Source: Okoguard Aerial Jumper Cable 15kV 90 $\mathrm{C}$ Rating ........................................1

Figure 1.2. EPR Specimen Cut from Cable Prior to Dog Bone Templating ............................................1

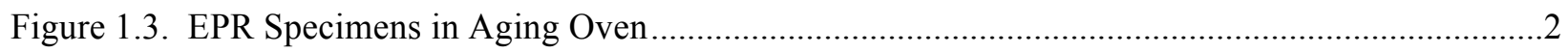

Figure 1.4. Constraining of EPR Specimens During Heating.............................................................2

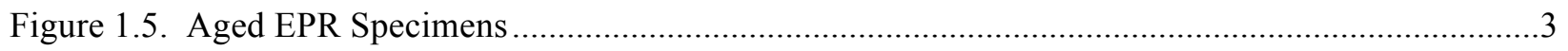

Figure 1.6. EPR Specimen Cross Sections. Ages in EAB indicated. .....................................................

Figure 1.7. Decrease in Elongation to Failure with Oven Aging ..........................................................

Figure 2.1. EPR Specimens Soaking in Chemical Rejuvenation Treatment ...........................................4

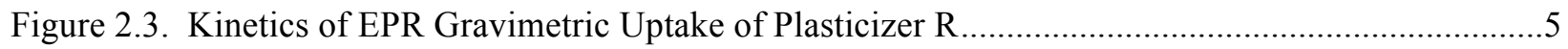

Figure 2.4. Kinetics of EPR Gravimetric Uptake of Silane T.............................................................6

Figure 3.1. Cross-sectional Area Changes in Treated Samples ...............................................................

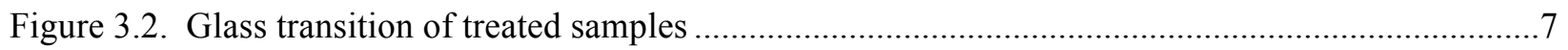

Figure 4.1. Example Stress-Strain Curves of Unaged EPR Illustrating Scatter ......................................8

Figure 4.3. Elongation at break of untreated and treated samples ......................................................

Figure 4.4. 50\% Modulus with Treatment ..........................................................................................10

Figure 5.1. Repair scheme for damaged EPR: Undamaged EPR (left); Oxidatively damaged EPR treated with plasticizer (center); and Repaired EPR (right) ...........................................................11 


\subsection{EPR Cable Aging}

Medium voltage ethylene-propylene (EPR) insulation material was obtained from The Okonite Company in the form of 1-inch outer diameter Okoguard Aerial Jumper Cable (Catalog number 303-211944). Figure 1.1 illustrates the construction of the EPR cable used for the experiments. Figure 1.2 illustrates the EPR insulation that was manually removed from the stranded copper conductor, stripped clean of the strand screen and cut into dog bone specimens conforming to ASTM D412 Die C specifications for subsequent tensile testing. Approximately 300 specimens were heated at $140^{\circ} \mathrm{C}$ under circulating air to simulate long term in-use thermal aging, with regular rotation of samples among locations within the temperature-controlled oven for even exposure. Elongation at break (EAB), the change in length a specimen will tolerate before it fails relative to its initial length, was used as the key criteria for material degradation relative to thermal exposure time. Figure 1.7 below reveals the trend of EAB with thermal exposure time, and shows reduction from $\sim 350 \%$ initial value to $\sim 50 \%$ end-of-life equivalency to occur in $\sim 50$ days at $140^{\circ} \mathrm{C}$. The tensile strength of the exposed samples (displayed below in Figure 4.3) illustrates a similar trend in property degradation.

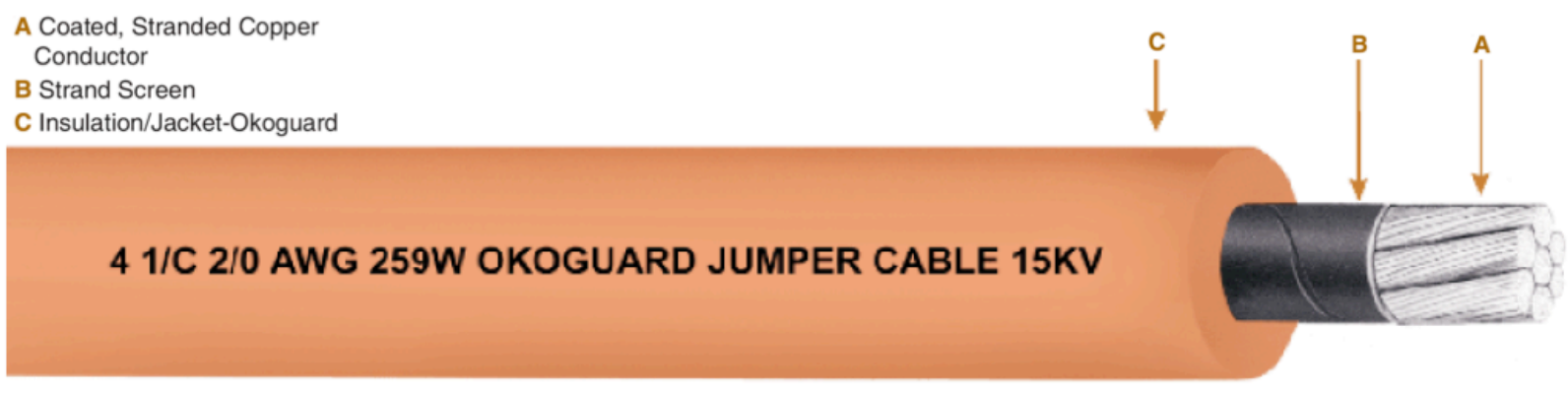

http://okonite.com/Product_Catalog/section6/index.html

Figure 1.1. EPR Source: Okoguard Aerial Jumper Cable $15 \mathrm{kV} 90^{\circ} \mathrm{C}$ Rating

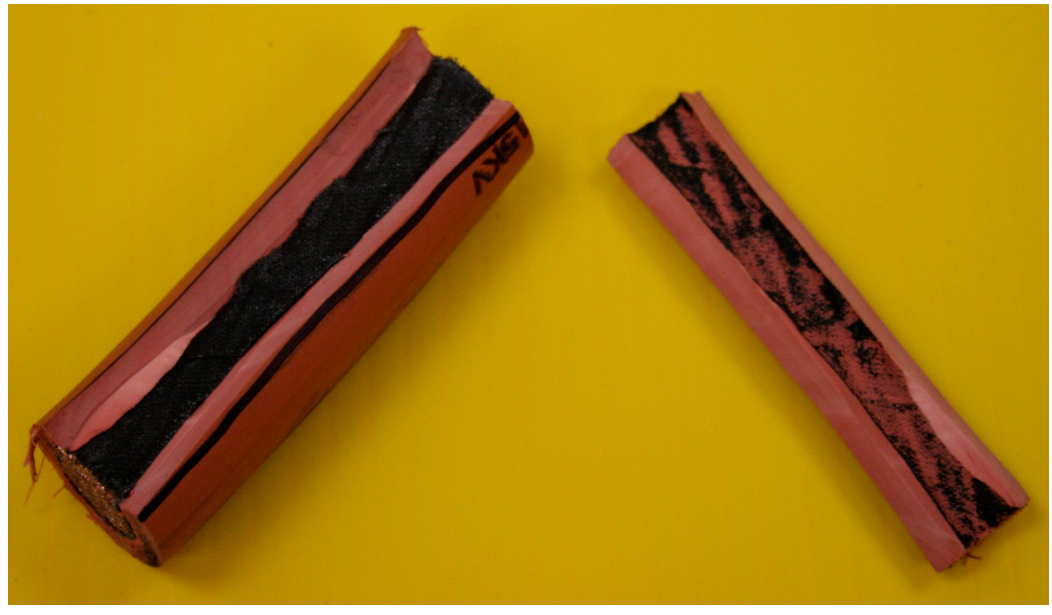

Figure 1.2. EPR Specimen Cut from Cable Prior to Dog Bone Templating 
Figure 1.3 illustrates the layout of the specimens assembled in the recirculating air oven. An aluminum plate was placed on top of the samples to help maintain flatness in the specimen during thermal exposure as shown in Figure 1.4. The plates supporting the samples were rotated every week to better homogenize the thermal exposure and minimize interference from possible hot zones in the oven.

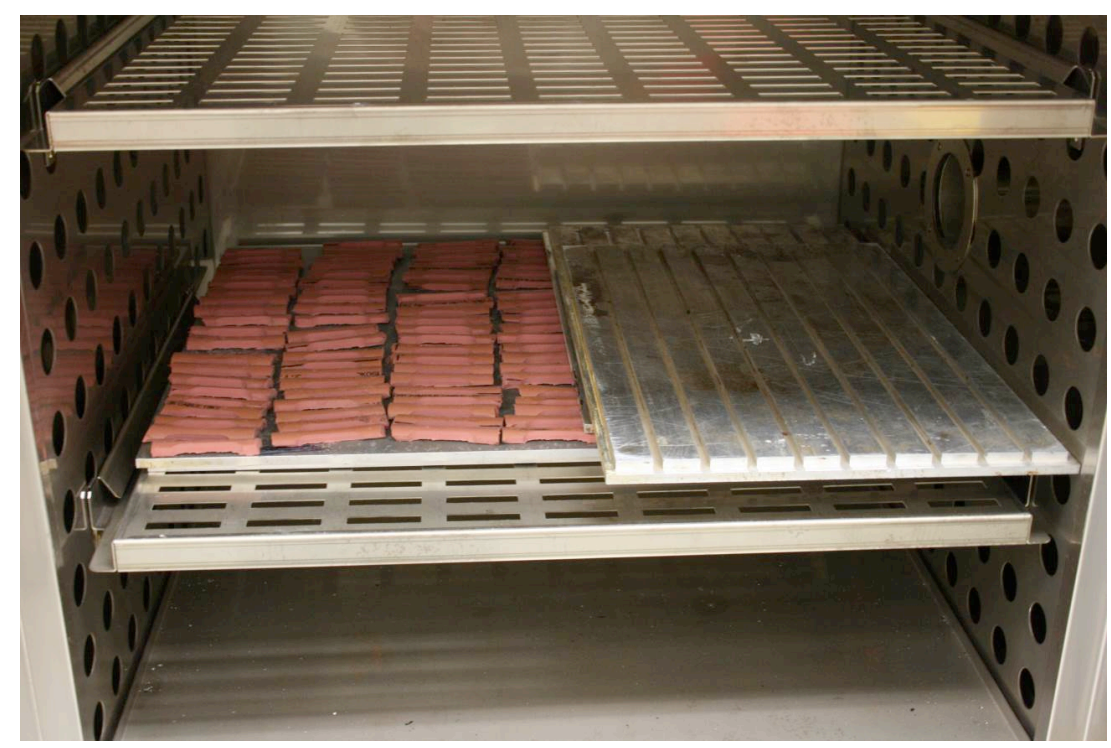

Figure 1.3. EPR Specimens in Aging Oven

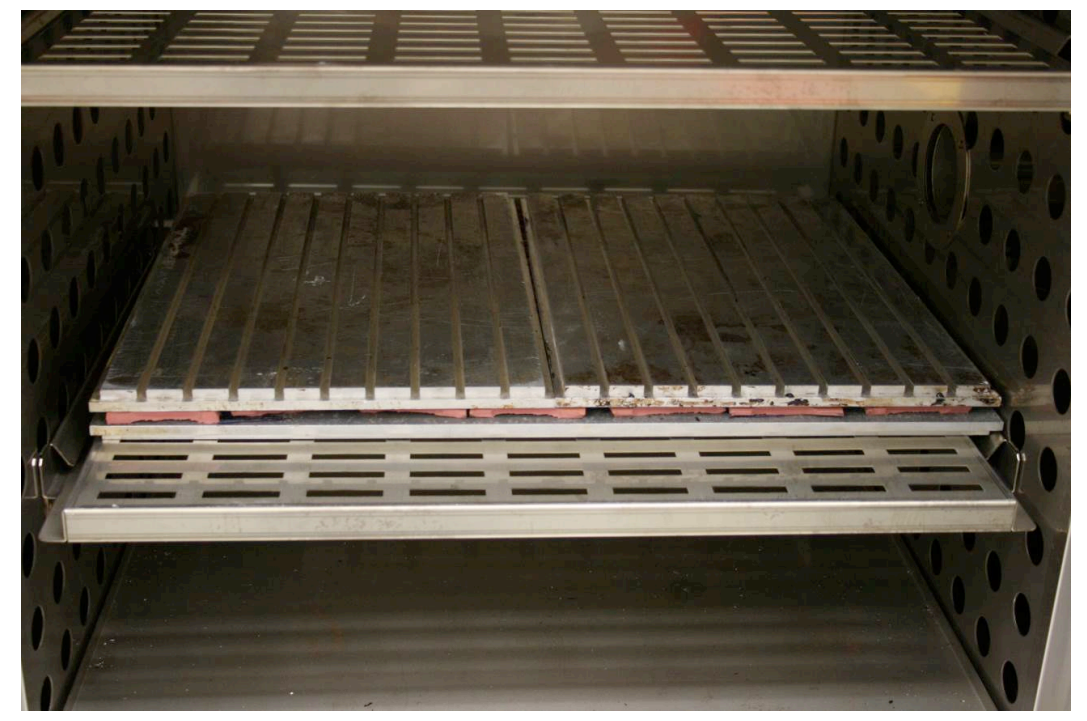

Figure 1.4. Constraining of EPR Specimens during Heating

During thermal exposure the specimens are sampled from the trays and evaluated to determine EAB relative to original EAB. The tensile specimens shown in Figure 1.5 were cooled and collected for chemical treatment absorption experiments.

Figure 1.6 displays specimen cross sections evaluated for uniformity in aging. The coloration appears very uniform across the cross section. Previous thermal exposures at higher temperatures resulted in non- 
uniform coloration across the specimen revealing diffusion-limited oxidation, indicated by a darker color around the perimeter of the cross section and a lighter coloration through the specimen interior.

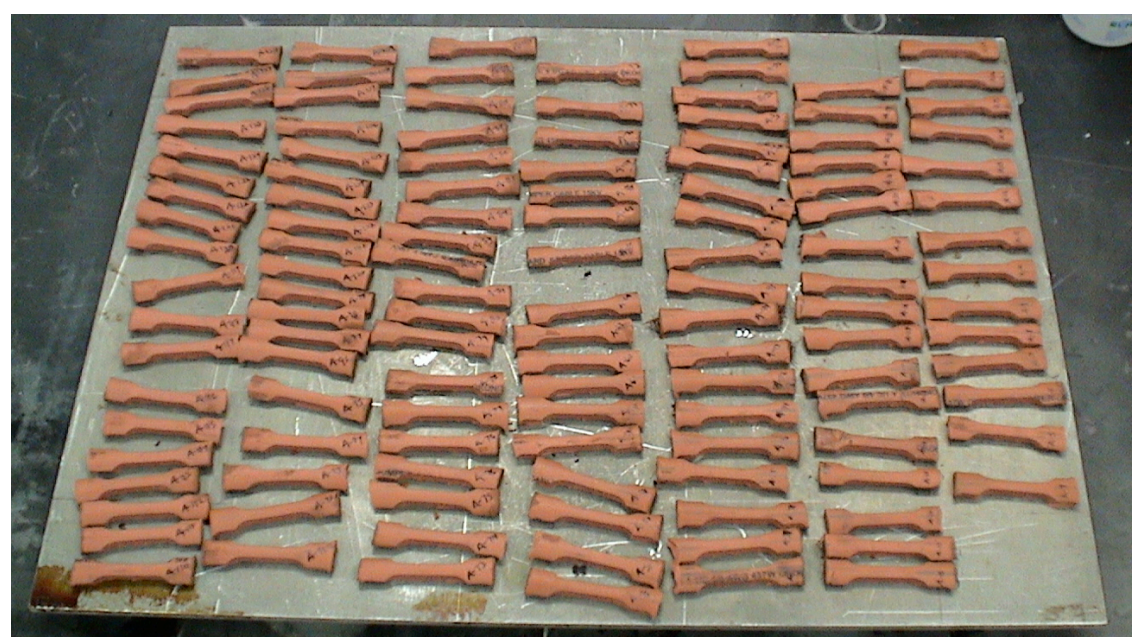

Figure 1.5. Aged EPR Specimens

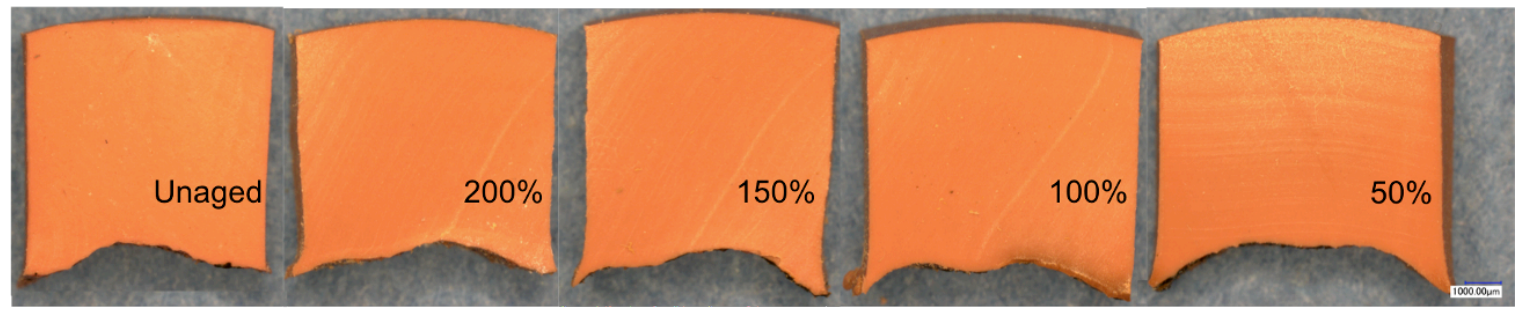

Figure 1.6. EPR Specimen Cross Sections. Ages in EAB indicated.

The project targeted 200, 150, and 100\% EAB for testing plasticization for EAB restoration. As the samples were aging, specimens were removed from the oven and tested at various times. Figure 1.7 shows the aging of the EPR insulator over time. This information allows for determining and predicting when the specimens should be sampled so as not to over expose the specimens for the targeted EAB. The groups of specimens were collected and further exposure was performed on those requiring lower EABs for the other groups. The 200 and $150 \%$ EABs have only one day separating them due rapid reductions in properties during this time frame. 


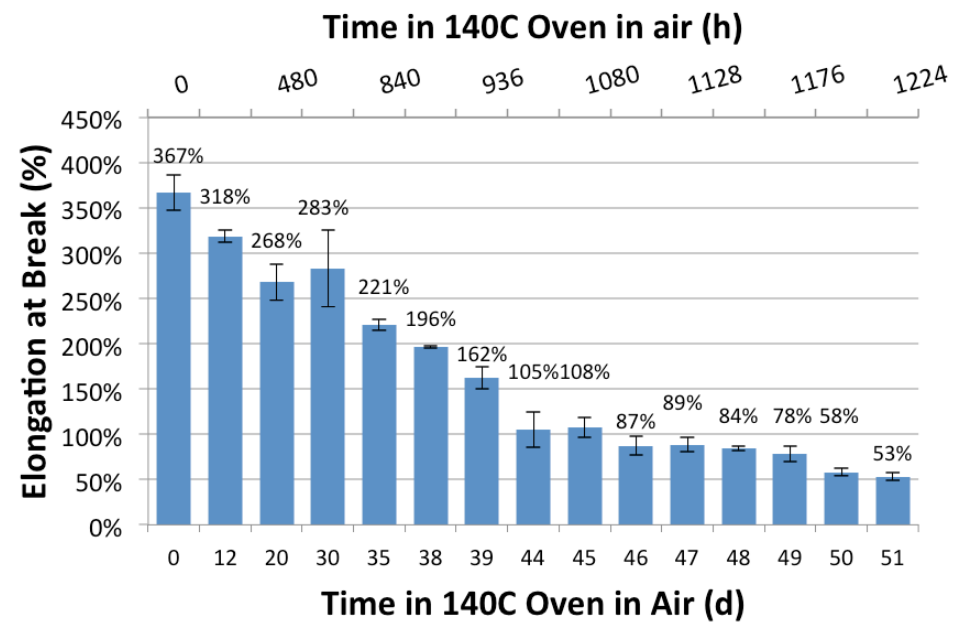

Figure 1.7. Decrease in Elongation to Failure with Oven Aging

\subsection{Rejuvenation Treatment}

Chemical treatment of aged EPR samples has been targeted to reverse the effects of the thermal degradation of the samples by recovering robustness as measured by EAB. Treatments have been applied by soaking aged EPR dog bones in treatment solutions at room temperature as shown in Figure 2.1. The two initial candidate treatments currently being investigated are an elastomer plasticizer, "Plasticizer R" (P-R), and a reactive organosilane, "Silane T" (S-T). Uptake kinetics for the treatments were followed gravimetrically and determined for each treatment for EPR samples of different functional ages: EAB values of $367 \%, 200 \%, 150 \%, 100 \%$ and $50 \%$. The procedure includes removing from soak solution, wiping, and massing at least 3 specimens with a microbalance for each scenario. Dog bone gauge section dimensions where also measure before returning the specimens to the soak solution.

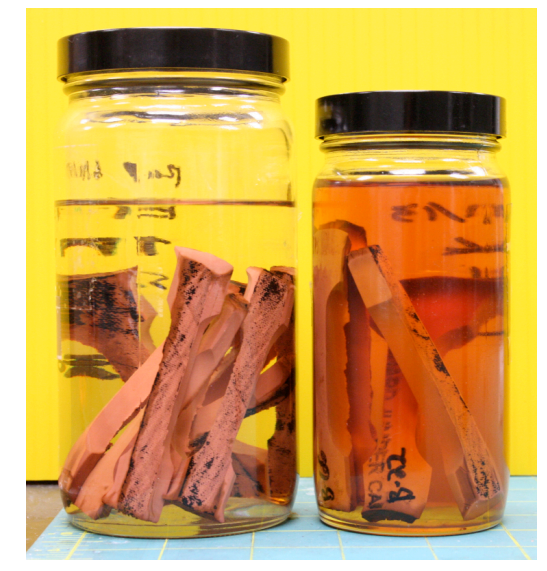

Figure 2.1. EPR Specimens Soaking in Chemical Rejuvenation Treatment 


\subsection{Plasticizer $\mathbf{R}$}

A commercially available elastomer plasticizer, referred to here as "Plasticizer R" or "P-R" was used as a solvent in which to soak aged EPR samples. After 15 days of soaking, unaged EPR sample mass uptake for P-R reached almost $25 \mathrm{wt} \%$. Ultimately aged 50\% EAB EPR samples exhibited 10wt\% P-R uptake after 15 days.

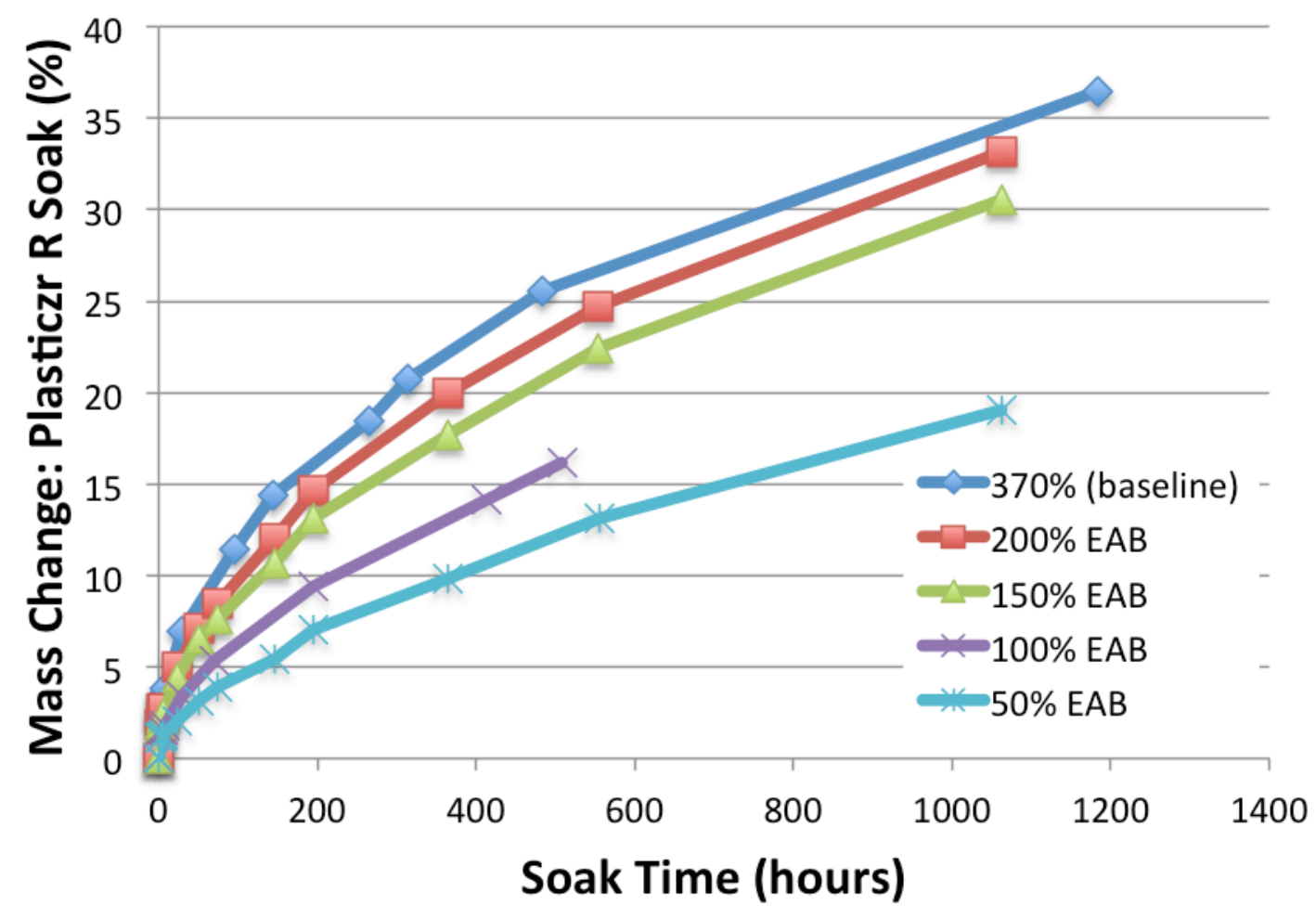

Figure 2.2. Kinetics of EPR Gravimetric Uptake of Plasticizer R

Figure 2.3 demonstrates with P-R that absorption rate is influenced by the stage of thermal degradation of the EPR. These data are useful for determining the total amount of time required to achieve desired levels of plasticization with different aged specimens. For example, a nuclear power plant cable with a $150 \%$ EAB would need to be exposed for a minimum of 200 hours to reach $12 \%$ absorption of P-R with the related mechanical property improvements discussed in Section 3 below.

\subsection{Silane T Reactive Organosilane}

The reactive organosilane with hydrophobic structure, referred to here as "Silane T" or "S-T", contains three funcionational sites that are available to react with hydroxyl surface groups that form during oxidation in thermally aged EPR. 


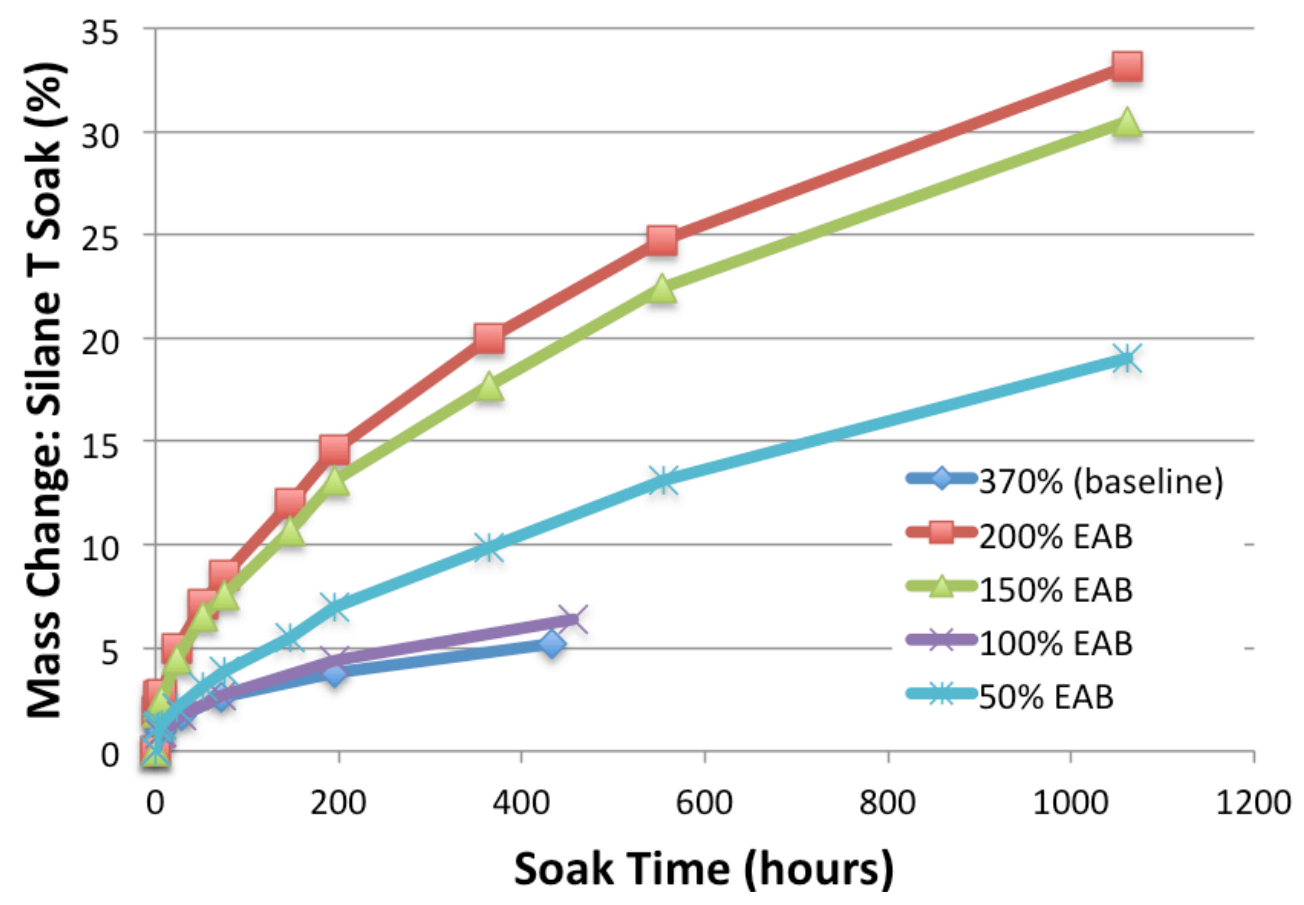

Figure 2.3. Kinetics of EPR Gravimetric Uptake of Silane T

Absorption rates for silane-soaked specimens did trend as consistently with specimen EAB at the plasticizer-soaked specimens did. The baseline (unaged) specimens were run twice with the same results. The data indicates that the thermal degradation enhances the adsorption rate.

\subsection{Physical Testing}

Physical testing of the soaked specimens indicate the physical changes the specimens undergo during aging and adsorption. Key indicators such as swelling and glass transition temperature assist in determining the physical and chemical effects of the adsorption. Figure 3.1 illustrates the absorption effects of swelling of the cross sectional area with the two different plasticizers. The plasticizer $\mathrm{R}$ has the largest effect on swelling, up to $25 \%$ with the $150 \%$ EAB specimens. However, the impact on absorption and swelling indicates a significant drop in swelling at $100 \% \mathrm{EAB}$. The Silane T treatment has a much different performance on swelling. As the EAB reduces, specimen dimensions actually decrease with absorption treatment at similar mass increases at which absorbed plasticizer produce increase in dimension. This may be due to the reactive nature of the silane treatment in which chemical bonds with the EPR matrix are formed in contrast to the solute/solvent interaction between EPR and plasticizer. 


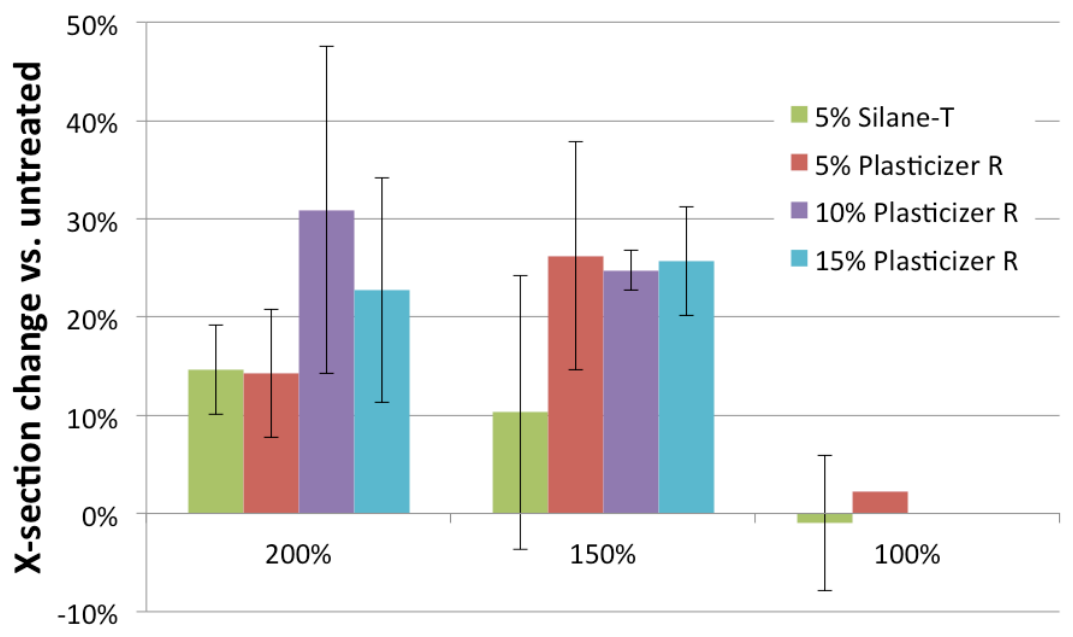

Elongation at Break

Figure 3.1. Cross-sectional Area Changes in Treated Samples

Figure 3.2 reveals the impact of absorption treatments on glass transition temperature and confirms that Plasticizer R has the largest effect. Plasticizer R reduces the glass transition temperature of the $200 \%$ EAB specimens by $20^{\circ} \mathrm{C}$ with only a $5 \%$ absorption and an additional $8^{\circ} \mathrm{C}$ with another $5 \%$ absorption. The $150 \%$ EAB specimens exhibited similar results except that the 5\% adsorption didn't trend like the $200 \% \mathrm{EAB}$, however, the end point at $10 \%$ adsorption appears to trend with the previous data set with a reduction of the nearly $43^{\circ} \mathrm{C}$. This data indicates that there is sufficient plasticization of the polymer.

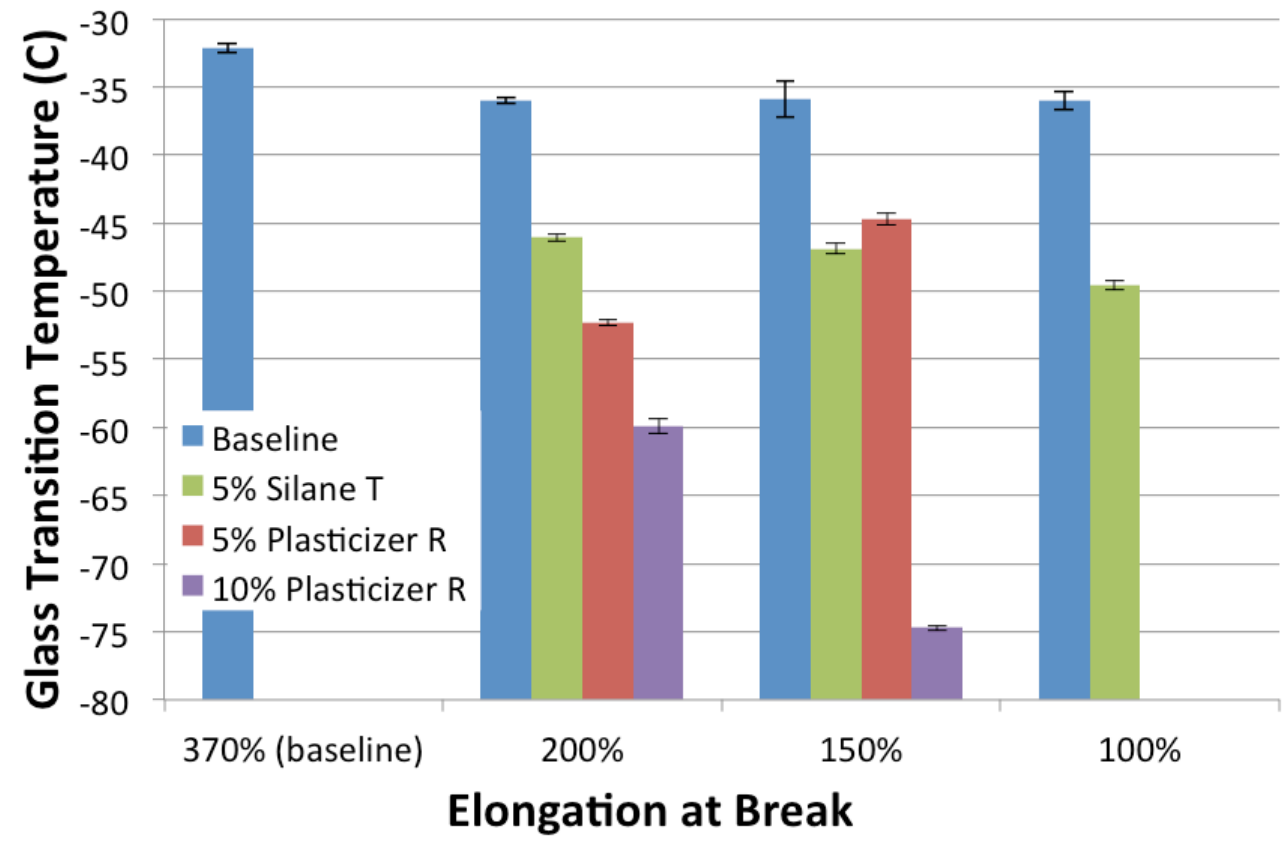

Figure 3.2. Glass transition of treated samples 


\subsection{Mechanical Testing}

Mechanical testing was performed on nearly 300 specimens. The measurement data of interest was ultimate tensile strength, elongation at break, and 50\% modulus. The data collected assisted in developing an understanding of the behavior in the material as it aged relative to the baseline. As the material chemically changes (damage) or loss of plasticizer, the mechanical properties undergo changes in all three measured areas. Figure 4.1illustrates the variation in the baseline material. It would be expected to have some level of variation with this type of specimen developed from the cable. The inner surfaces of the insulator are rough from the conductor surface being molded into it during extrusion. The rate of testing was 50cm/min with an ASTM D412 Die C geometry that was cut using a 1033 Tensilkut machine.

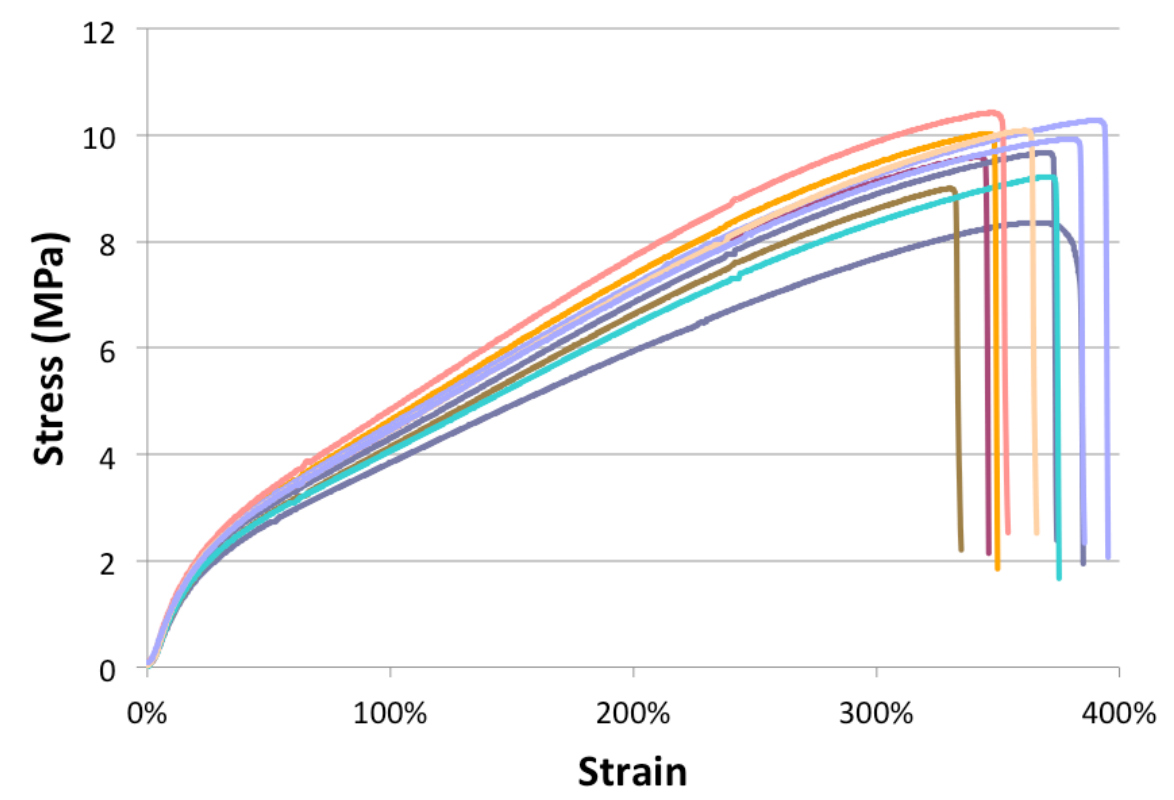

Figure 4.1. Example Stress-Strain Curves of Unaged EPR Illustrating Scatter

In Figure 4.2 and 4.3, the baseline elongation at break and ultimate tensile strength trend down with thermal exposure over time as would be expected. The plasticizer treatments show the impact of absorption levels on the strength and the elongation. It appears that swelling from the plasticizer $\mathrm{R}$ samples is accumulating internal stress that reduces the strength and elongation at the 150 and 200\% EAB set. The silane T has lower levels of swelling as explained in section 3 and reduces the amount of accumulated stress. However, the plasticizer R does not appear to be healing the damaged polymer, but does have an impact on plasticizing the polymer system as shown by the reduction in the glass transition temperature and modulus effects. The silane $\mathrm{T}$ is a reactive system that is designed to react with any hydroxyl groups formed during oxidation which is a possible explanation for a different behavior of the plasticizer R. 


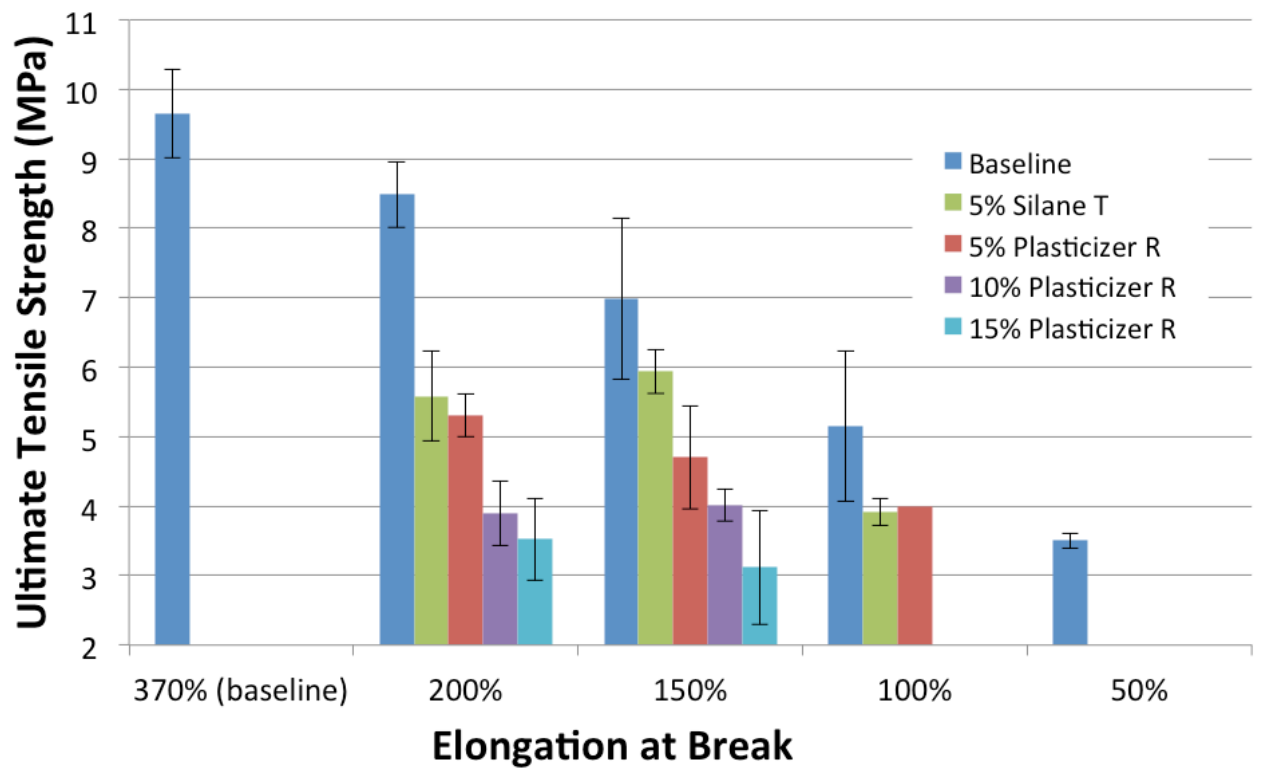

Figure 4.2. Ultimate tensile strength of untreated and treated EPR

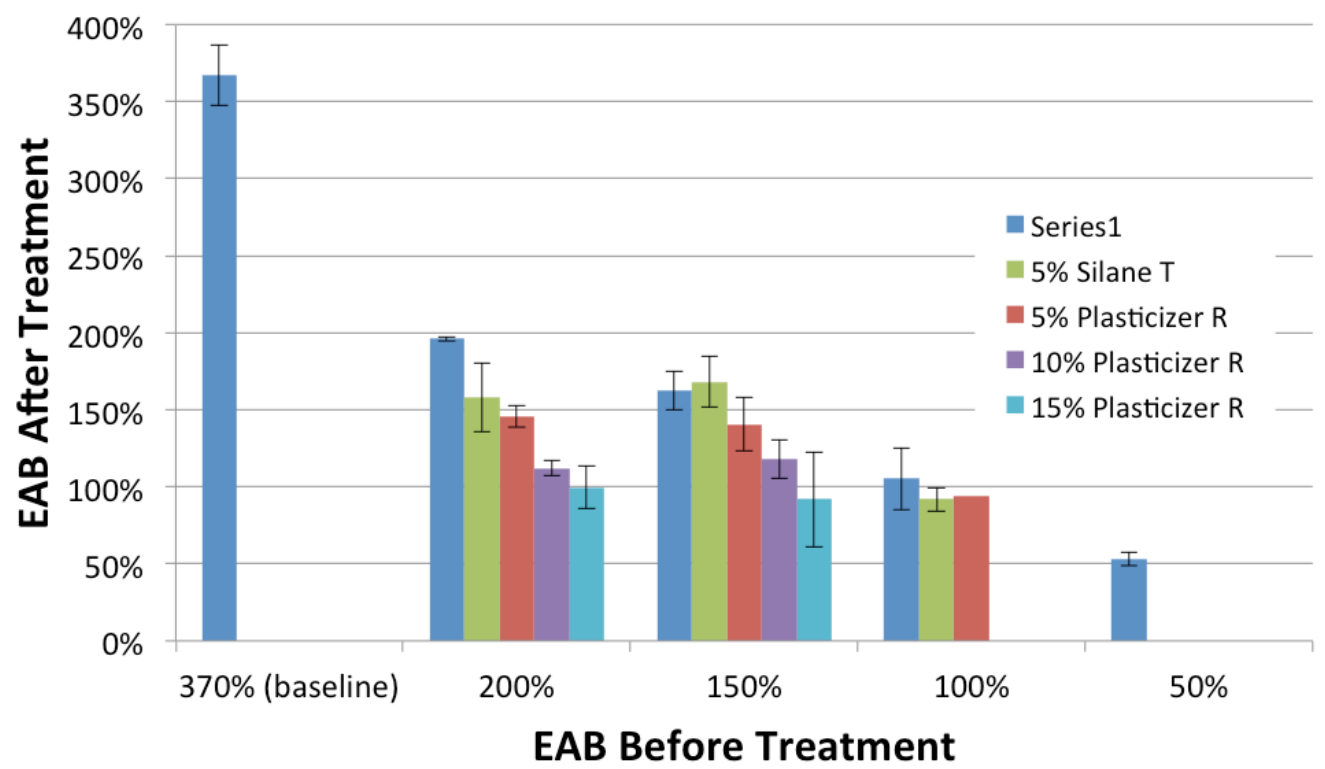

Figure 4.3. Elongation at break of untreated and treated samples

The biggest impact seen with the plasticizer is its effect on making the material more compliant by reducing the modulus of the material. The measurements were done on a secant modulus determined at $50 \%$ elongation. Typical rubber measurements at done at 100 and $200 \%$ elongations, but since the samples are being tested down to $50 \% \mathrm{EAB}$, it was determined to maintain an modulus measurement that would be consistent for all samples. Figure 4.4, shows the baseline material increasing in stiffness with thermal aging, and the treated samples show significant decreases. The materials indicate changes exceeding $40 \%$. 


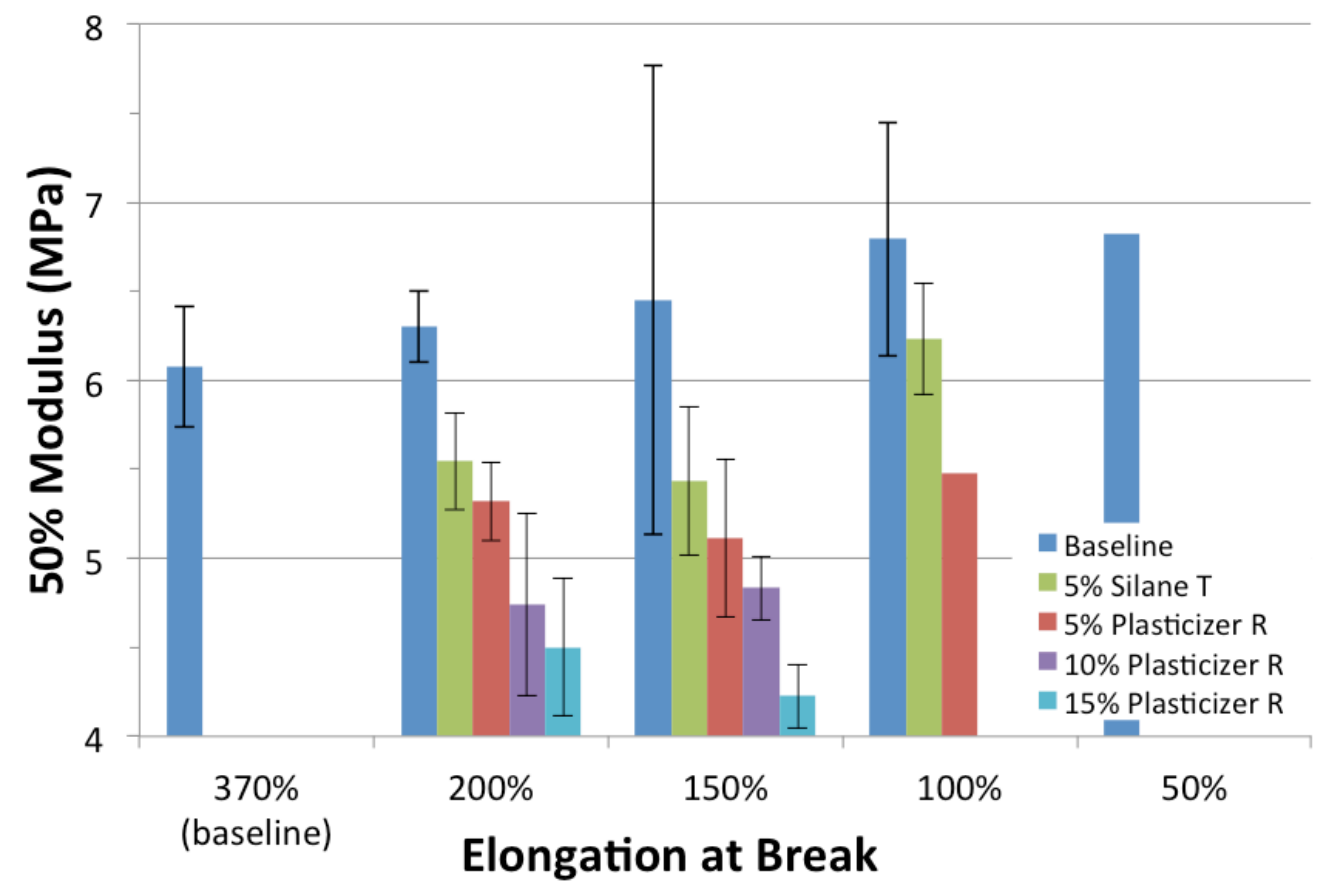

Figure 4.4. $50 \%$ Modulus with Treatment

\subsection{Conclusions and Status}

The motivation for this project comes from the need to extend the working life of in-containment cables at nuclear power plants. Replacement of existing safety-related power, instrumentation, and control cables represents significant costs in materials and plant shut down time. Therefore, it is of significant importance to develop methods for lengthening the remaining useful life of existing cables.

Our efforts of the past year have shown that plasticizing aged cable insulation is effective in recovering mechanical properties as indicated by positive changes in modulus and glass transition and predictable uptake kinetics relative to cable insulation age. It was also determined that the polymer chains that have been damaged need to be repaired in order to increase the strength and the elongation at break of the material. Future efforts will focus on developing a chemical strategy for repairing the damaged polymer chains with long chain chemistries that will allow for improved elongation and strength.

Oxidative degradation in semicrystalline polymers such as EPR proceeds by cross-linking of polymer chains at elevated temperatures $\left(>150^{\circ} \mathrm{C}\right)$ and by chain scission at lower temperatures. Load-bearing tie molecules in the amorphous regions between crystalline regions are relatively strained and more susceptible to oxidative cleavage. It is cleavage of these bonds that results in loss of EPR mechanical properties as illustrated by reduction in EAB with oxidative aging. Thermal energy can lead to 
production of macroalkyl radicals, which then propagate with the uptake of oxygen and formation of peroxides and peroxide radicals during the auto-oxidation process. During chain scission the peroxide radicals terminate with the formation of carbonyl, ether, and other characteristic bonds that are amenable to detection by FTIR spectroscopy via their vibrational signatures. In the next phase of this work we plan to use FTIR, perhaps in combination with derivatization reactions, to determine the major terminal functional groups resulting from thermal-oxidative chain scission in the EPR we are studying. We will attempt to restore $\mathrm{EAB}$ mechanical properties to the degraded material by reinforcing the load-bearing capacity of tie molecules through reintroducing chemical linkages between portions of the cleaved polymer macromolecules. Reactive chemical approaches will be tuned to the specific nature of the broken bonds in a targeted effort to restore mechanical performance and effectively reverse thermooxidative aging. Figure 5.1 illustrates approaches to recovery of EAB in EPR that has experienced oxidative damage. Undamaged EPR molecules are representatively illustrated in the left panel of the figure. In the center panel, a plasticizer is shown to be able to affect the motion between EPR molecules, but not to restore EAB by repairing the ability of damaged molecules to bear loads when the EPR is stressed. In the right panel of the figure, the envisioned chemical rejuvenation approach is illustrated in which reactive molecules target oxidative damage points and restore mechanical continuity to the polymer matric, thus recovering EAB performance.

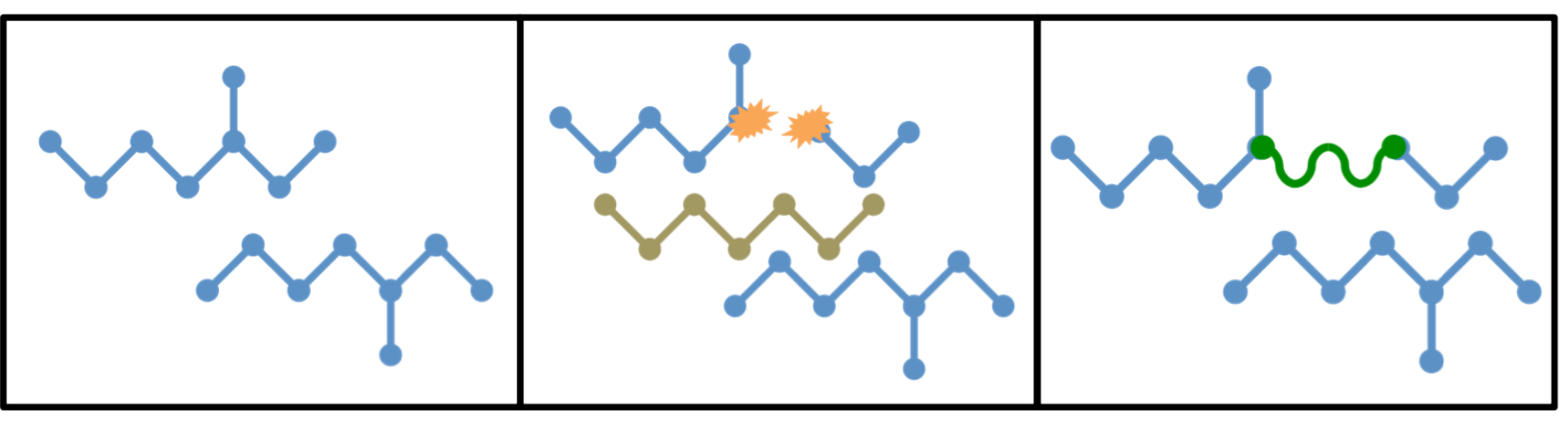

Figure 5.1. Repair scheme for damaged EPR: Undamaged EPR (left); Oxidatively damaged EPR treated with plasticizer (center); and Repaired EPR (right) 


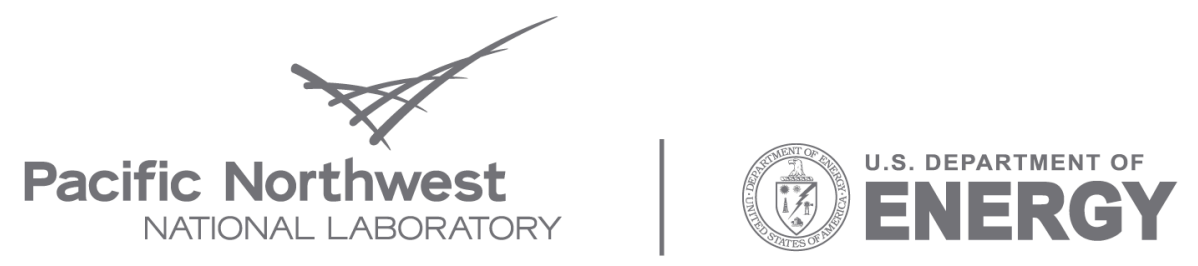

Proudly Operated by Battelle Since 1965

902 Battelle Boulevard

P.O. Box 999

Richland, WA 99352

1-888-375-PNNL (7665)

www.pnl.gov 